\title{
Laser-assisted Transforaminal Endoscopic Lumbar Discectomy: Technical Pearls for Prevention of Complications
}

Yong Ahn

Sang-Ho Lee

Department of Neurosurgery, Wooridul Spine Hospital, Seoul, Korea

Received November 3, 2013

Revised December 11, 2013

Accepted December 13, 2013

\footnotetext{
Correspondence

Yong Ahn

Department of Neurosurgery, Wooridul Spine Hospital, 47-4, Chungdam-dong, Gangnam-gu, Seoul 135-100, Korea

Tel: +82-2-513-8945

Fax: $+82-2-513-8146$

E-mail: ns-aydahanmail.net

(C) Korean Society for Laser Medicine and Surgery

(c) This is an open access article distributed under the terms of the Creative Commons Attribution NonCommercial License (http://creativecommons.org/ licenses/by-nc/3.0) which permits unrestricted noncommercial use, distribution, and reproduction in any medium, provided the original work is properly cited.
}

\begin{abstract}
Laser-assisted transforaminal endoscopic lumbar discectomy is regarded as an effective treatment option for herniated lumbar disc disease. Technical evolution has enabled selective endoscopic removal of an epidurally extruded disc fragment with assisted laser. As a result, the clinical applications for this technique are broadening. However, with increased use of laser and endoscopic techniques, related complications such as postoperative dysesthesia, dural tears, hematoma, infection, and visceral injury emerge as important problems. In addition, considerable radiation dose during the procedure may cause a health problem to medical personnel. There are several technical pearls that can be used in the effort to increase the effectiveness of endoscopic laser procedures and prevent complications. Initial placement of the working cannula should be as close to the target as possible. Complete herniotomy after adequate annular release is the key to success. Free mobilization of the nerve root is the definitive end-point of the procedure.
\end{abstract}

\section{Key words}

Laser; Transforaminal; Endoscopic; Lumbar discectomy; Complication 


\section{INTRODUCTION}

Laser-assisted transforaminal endoscopic lumbar discectomy is regarded as an effective treatment option for treating soft lumbar disc herniation. The benefits of this procedure include preservation of posterior structures and comparable clinical outcome to the conventional microdiscectomy. ${ }^{1-4}$

The basic concept of this procedure has been evolved. At first, the basic concept was to obtain indirect neural decompression of the central nucleus and to reduce the intradiscal pressure. Subsequently, the decompression focus moved onto subannular-protruded disc herniation. Therefore the target pathology was mainly contained disc herniation. And now, the aim of this procedure is to perform selective epidural fragmentectomy and direct neural decompression, while preserving the central nucleus. ${ }^{5,6}$

Several randomized trials have demonstrated the effectiveness of this procedure. ${ }^{2,7-9}$ However, as the clinical application of this procedure becomes wider, various unexpected adverse events are emerging. ${ }^{10-13}$ Furthermore, radiation exposure during this procedure may be considerable. Therefore, it may cause a serious health problem to the surgeons or medical personnel.

The purpose of this review article is to describe various adverse effects associated with laser-assisted endoscopic discectomy and demonstrate proper technical pearls to increase effectiveness and safety of this procedure.

\section{SURGICAL TECHNIQUE}

The procedures are conducted according to the standard transforaminal endoscopic laser discectomy technique. 2,6,7,9,14

\section{Transforaminal approach - needling and discography}

The patient's position is a prone on a radiolucent table with mild flexion of the knee. The patient is an aware status during the procedure to get the feedback from the patient if there is any change in symptoms and signs. The skin entry point is typically approximately 8 to $13 \mathrm{~cm}$ from the midline. The entry point is determined according to the size of the patient, the dimensions of the facet joints, and the location of the pathologic focus. To determine the appropriate entry point, preoperative CT and MRI should be reviewed. A spinal needle is inserted after infiltration of local anesthetic. Local anesthetics such as Dormicom and Fentanyl can be administrated as required. The needle tip is landed at some point of the medial-to-lateral pedicular line on the anteroposterior (AP) fluoroscopic projection, and at the posterior vertebral line on the lateral projection. At this time, an epidurogram and a preemptive epidural adminstration of $0.5 \%$ lidocaine is performed to prevent approach-related pain. After the insertion of the needle into the disc, $1 \mathrm{ml}$ indigocarmine dye is mixed with $6 \mathrm{ml}$ contrast medium and injected into the disc. Pathological structures which are firm, resilient, and unstained can be easily distinguished from normal disc tissues.

\section{Transforaminal approach - placement of working sheath and endoscope}

The needle is then replaced by a guide wire and an obturator with a small stab incision. The tapered cannulated obturator is slid over the guide wire and introduced gently into the disc through the foraminal window. A bevel-ended working sheath is then introduced over the obturator. During this step, a moderate to severe approach-related pain may develop because of irritation to the exiting nerve root or any inflamed epidural tissues. To help reduce approach-related pain and exiting nerve root irritation, sequential dilation technique using various sized obturators is useful. After the obturator is withdrawn, an ellipsoidal endoscope, with an eccentrically placed working channel and 2 irrigation channels, is inserted.

\section{Laser-assisted endoscopic discectomy and epidural decompression}

Initial endoscopic view is usually mixture of soft tissue and disc material. The surgeon should remove the soft tissues and subannular disc material as an initial decompression. Then, the layers of intraforaminal structures can be defined. These include the dural sac, epidural fat, posterior longitudinal ligament, inflamed annulus, and disc material. Through the endoscopic visualization, the surgeon can recognize the herniated disc fragment and annular fissure. The herniated fragment is usually adhered to the fibrotic annular fissure, and the release of annular anchorage before discectomy is essential. The releasing step can be performed using a side-firing holmium:yttrium-aluminum-garnet (Ho:YAG) laser. The laser setting can be adjusted according to the characteristics of the tissues. The power of laser (Watts) is determined by the laser energy (Joules) and rate of laser beam $(\mathrm{Hz})$ (Watts=Joules $\times \mathrm{Hz}$ ). For routine soft tissue ablation, 40 watts (2.0 Joules, $20 \mathrm{~Hz}$ ) of laser is usually used. The laser power can be increased up to 60 to 100 watts for tough fibrotic tissues or bone. 
The use of side-firing laser has several benefits. Firstly, it may ablate the soft tissues such as herniated disc, pathologic ligaments and hypertrophied bone tissues. A sophisticated decompression with less bleeding is possible. Secondly, the thermal conduction rate to the adjacent tissues is very low and therefore, there is little risk of thermal injury to the neural tissues. Finally, it is very useful to clean the visual field by removing the soft tissue debris. It is very difficult to remove small debris with mechanical tools in the very small endoscopic field. As the fibrotic annular anchorage is released and the annular fissure is opened widely, the blue-stained herniated disc fragments become loose and mobile. The free fragment is then removed by endoscopic forceps and laser. As the decompression process gradually reduces the back muscle tension, the angle of the endoscope can become more horizontal, thereby pivoting on the foramen. The surgeon can adjust the approach angle as needed. The flexibility of the approach angle is one of the benefits of the transforaminal approach in comparison to the conventional posterior approach. ${ }^{6,15}$ With this levering technique, the surgeon can examine the full undersurface of the annulus and even remove the epidurally herniated disc fragments. Finally, epidural dissection is performed, and the decompressed dural sac or nerve roots are identified. When the end-point of the procedure, i.e., free mobilization of neural tissue, is achieved, the endoscope is withdrawn and a sterile dressing is applied over a one point subcutaneous suture. In the absence of postoperative problems, all patients are permitted to go home within 24 hours.

\section{DISCUSSION}

Several randomized controlled trials have demonstrated the effectiveness of endoscopic discectomy in comparison to conventional open discectomy. ${ }^{2,-9}$ Hermantin et al. ${ }^{2}$ demonstrated that the rate of satisfactory outcomes was the same in the endoscopy and open discectomy groups. However, the period of postoperative disability or narcotic use was shorter in the endoscopy group. Ruetten et al.? reported that the clinical outcomes of the endoscopic technique are equal to those of the microsurgical technique, with significant advantages in back pain, return to work, complications and traumatization. Technical evolution of this procedure now enables the selective removal of epidurally extruded disc fragments in the lumbar spine. Ironically, the occurrence of complications in endoscopic discectomy may be closely related to its technical evolution. As surgeons become overconfident in performing the technique and the use of endoscopic discectomy is broadened to include cases of greater complexity, the risk of unexpected adverse events may increase.

\section{Injury to neural structures and dural tear}

The most common neural problem is approach-related irritation of the exiting nerve root, dorsal root ganglia, or possibly the furcal nerve in the foraminal area. ${ }^{6,9,13-17}$ Approach-related irritation can be caused by the approach needle, bulky obturator, or the working cannula during the approach step. During the procedure, patients are conscious under local anesthesia; therefore, neural irritation by approach instruments may cause severe pain, because of which the procedure may have to be stopped. Postoperative dysesthesia from exiting nerve root damage may cause significant sequelae. If neural injury occurs during the posterior open discectomy, it may occur on the traversing nerve root, which is already compromised. In transforaminal endoscopic approach, however, the injury may occur on the fresh dorsal root ganglion, and the patient may complain of a new symptom- postoperative dysesthesia. ${ }^{16}$ The occurrence of this complication may be particularly stressful for the surgeon because the dysesthesia usually affects the dermatome of the exiting nerve root, and the symptoms differ from the patient's preoperative symptoms. A deviation of the needle, dilator and cannula to the cranial part of the neuroforamen can affect the exiting nerve root. Excessive intraoperative manipulation by instruments or laser also can cause this complication. The less common, but more serious, complication of neural tissue is an intraoperative dural breach. ${ }^{5}$ Dural injury may occur in 2 forms: a mechanical tear caused by surgical tools or thermal injury caused by laser. If dural injury is unrecognized or untreated, serious neurological deficits may develop. Our published data ${ }^{5}$ demonstrated that patients in the unrecognized dural tear group showed less favorable clinical outcomes than the patients with recognized dural tear did, with substantial motor weakness.

\section{Injury to vascular structures and hematoma}

Although the occurrence of hematoma is relatively rare, vascular damage usually develops into a postoperative hematoma. The unique hemorrhagic complication of this procedure is a retroperitoneal hematoma. ${ }^{13,18}$ Injury to the radicular lumbar artery or its branches during the transforaminal approach or extraforaminal instrumental work may result in hematoma formation in the loose retroperitoneal space. ${ }^{18}$ In the case of a large hematoma 


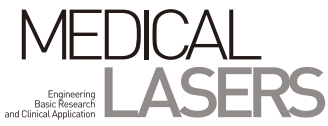

(>500 ml), urgent surgical evacuation is required. Another possible vascular event is a postoperative epidural hematoma, the incidence and risk factors of which are not clear. In most cases, postoperative epidural hematoma is subclinical or self-limiting. However, occasionally, revision surgery may be required, especially after extensive epidural exploration or bony sculpturing.

\section{Injury to abdominal contents}

The approach needle can perforate the peritoneal sac during its course to the foraminal window if the skin entry point is chosen too far laterally and the trajectory is kept vertical. An inadvertent tap of the intestine during initial needle insertion may contaminate the disc space, leading to secondary spondylodiscitis after endoscopic discectomy. ${ }^{19-21}$ Another possible scenario is inadvertent advancement of a needle or other instruments beyond the anterior disc margin. Bowel or ureter injury resulting from inadvertent use of a laser or biting instrument beyond the anterior annulus has been reported. ${ }^{22,23}$ To avoid these complications, the needle or instrument position should be regularly confirmed on fluoroscopic views, especially the lateral view. It is important to keep the needle tip posterior to the posterior vertebral line. If intestinal injury is suspected, the needle should be changed immediately.

\section{Infections}

The most common infection problem is spondylodiscitis. ${ }^{20,21}$ According to the published data, ${ }^{21}$ the occurrence of postoperative spondylodiscitis is relatively rare after endoscopic disectomy compared to open surgery. However, the clinical manifestations of spondylodiscitis progress rapidly and are of a serious nature. The typical symptoms are severe back pain, possibly combined with leg pain, several days after the procedure. Elevated laboratory markers such as erythrocyte sedimentation rate (ESR) and C-reactive protein (CRP) appear to be more reliable than radiological findings in the early postoperative stage. ${ }^{24,25}$ Early MRI is not reliable as the sole method for detecting septic spondylodiscitis. ${ }^{26,27}$ For definitive bacteriological diagnosis, disc punctures under fluoroscopic or endoscopic guidance are recommended. First-line treatment consists of appropriate antibiotic therapy with motion restriction. In case of unresponsiveness to medical therapy, decisive surgery such as an open debridement or interbody fusion is required. ${ }^{28}$

\section{Incomplete decompression and reherniation}

Incomplete decompression occurs because of a missed fragment or remanent lateral recess stenosis that significantly compresses the nerve root. ${ }^{13}$ The patients usually still suffer from radicular pain without a painfree interval and frequently require a second surgery. Incomplete decompression occurs due to technical difficulties or the failure to recognize if the decompression is sufficient. Incomplete decompression is more likely to occur in cases of migrated disc herniation or large central disc herniation with high canal compromise. 13,29,30 $^{2}$ To prevent this problem, adequate knowledge about the anatomical relationships and the ability to recognize the end-point of the procedure are essential. Another problem of incomplete decompression is reherniation of disc fragments after a pain-free period. After surgery, a hidden intradiscal herniated fragment may extrude from the same side or the contralateral side. A reliable recurrence rate has not been established, but some data demonstrate that the recurrence rate is similar to that of traditional open discectomy. ${ }^{13}$ To reduce recurrence, complete removal of the hernia mass (herniotomy), including the basal part and extruded parts, is important. However, herniotomy is not a radical removal of the disc; rather, it is the removal of a fragment that is sequestered from the maternal disc.

\section{Technical tips and tricks to prevent complications}

This has a steep learning curve, and the surgical outcome tends to be different between experts and beginners. ${ }^{31}$ Furthermore, surgeons usually do not learn endoscopic techniques during their residency or training course. There are several technical guidelines to increase effectiveness of endoscopic techniques and prevent complications. These guidelines can be summarized by 3 key words: landing, herniotomy, and ending.

\section{Landing las near to the target as possible)}

Adequate landing, which means an adequate transforaminal approach through the foraminal window, is the most important key to achieving success and preventing complications. The basic principle is that the landing point should be as close to the target as possible and that the exiting nerve root should not be irritated. According to the zone of herniation, the landing point and approach angle can be adjusted. For central and subarticular disc herniation, a horizontal approach to the medial pedicular line (shallow transforaminal approach) is recommended, and for foraminal and far-lateral disc herniation, the steep approach angle to the lateral pedicular line (steep extraforaminal approach) is recommended. ${ }^{32,33}$ The landing point and approach angle can be changed according to the level. For upper lumbar levels such as 
L1-2 and L2-3, a steeper approach and lateral landing are recommended. For lower lumbar levels such as L45 and L5-S1, a more horizontal approach and medial landing are recommended. At the L5S1 level, a high iliac crest may be a major obstacle to the standard transforaminal approach. In cases of low iliac crest, a shallow transforaminal approach is possible. However, in cases of high iliac crest, a modified technique with a more medial placement of the skin window and resection of the superior facet tip (endoscopic foraminotomy) should be applied. ${ }^{6,34}$ Regardless of the approach and landing used, the exiting nerve root should be protected during the approach. The leading edge of any instrument should be located away from the trajectory of the exiting nerve root. A more caudal approach along the superior facet surface is a useful technique to avoid the exiting nerve root. This prevents approach-related pain and postoperative dysesthesia. Finally, all instruments should be kept posterior to the posterior vertebral line before entry into the disc space. This is essential to prevent abdominal damage and injury to the radicular lumbar artery. Therefore, the initial needle insertion should be performed under lateral fluoroscopic guidance rather than the AP view.

\section{Releasing herniotomy (removal of the whole "iceberg")}

The herniated fragment should be separated from the tight annular anchorage and freed before removal. Complete release of annular anchorage can be performed using a side-firing laser and annulus cutter. This releasing step is essential because the instruments are relatively smaller and weaker than those used in conventional microdiscectomy. In general, the herniated fragment is composed of an epidurally extruded part and an intradiscal part, just like an iceberg. The whole "iceberg" must be removed, not just the tip. If any part of the iceberg is left, incomplete decompression or delayed reherniation may occur. For identifying a perfect herniotomy, there is 1 simple tip: "see the contralateral annular fissure." This is a useful indicator of a complete herniotomy.

\section{Ending (free mobilization)}

Many beginners usually ask: "What is the end-point of the endoscopic discectomy"? The end-point may be different according to the situation. The recommended end-point is free mobilization of neural tissue after complete herniotomy. In the surgical field, the end-point can be recognized by seeing the whole annular fissure and strong epidural pulsation of the dural sac and nerve root. At this point, the dural sac and the nerve root can be seen to "breathe." However, direct exposure of the traversing nerve root or dural sac is not recommended. An attempt to achieve wide exposure of the neural tissue involves the risk of dural tear or neural damage by instruments or laser. Moreover, excessive removal of the outer layer of the annulus or other mechanical barriers, including the epidural fat and various ligamentous structures, may cause recurrence, dysesthesia, epidural fibrosis, or postoperative instability. Therefore, an ideal end-point is complete herniotomy with an intact annular barrier, free mobilization of epidural neural tissues, and intact epidural fat and ligamentous structures.

\section{ACKNOWLEDGMENTS}

This study was supported by a grant from the Wooridul Spine Hospital.

\section{REFERENCES}

1. Kambin P, Brager MD. Percutaneous posterolateral discectomy. Anatomy and mechanism. Clin Orthop Relat Res 1987;(223):14554.

2. Hermantin FU, Peters T, Quartararo L, Kambin P. A prospective, randomized study comparing the results of open discectomy with those of video-assisted arthroscopic microdiscectomy. J Bone Joint Surg Am 1999;81:958-65.

3. Maroon JC. Current concepts in minimally invasive discectomy. Neurosurgery 2002;51(5 Suppl):S137-45.

4. Knight M, Goswami A. Management of isthmic spondylolisthesis with posterolateral endoscopic foraminal decompression. Spine (Phila Pa 1976) 2003;28:573-81.

5. Ahn Y, Lee HY, Lee SH, Lee JH. Dural tears in percutaneous endoscopic lumbar discectomy. Eur Spine J 2011;20:58-64.

6. Yeung AT, Tsou PM. Posterolateral endoscopic excision for lumbar disc herniation: Surgical technique, outcome, and complications in 307 consecutive cases. Spine (Phila Pa 1976) 2002;27:722-31.

7. Hoogland T, Schubert M, Miklitz B, Ramirez A. Transforaminal posterolateral endoscopic discectomy with or without the combination of a low-dose chymopapain: a prospective randomized study in 280 consecutive cases. Spine (Phila Pa 1976) 2006;31:E890-7.

8. Mayer HM, Brock M. Percutaneous endoscopic discectomy: surgical technique and preliminary results compared to microsurgical discectomy. J Neurosurg 1993;78:216-25.

9. Ruetten S, Komp M, Merk H, Godolias G. Full-endoscopic interlaminar and transforaminal lumbar discectomy versus 
conventional microsurgical technique: a prospective, randomized, controlled study. Spine (Phila Pa 1976) 2008;33: 931-9.

10. Ahn Y, Kim JU, Lee BH, Lee SH, Park JD, Hong DH, et al. Postoperative retroperitoneal hematoma following transforaminal percutaneous endoscopic lumbar discectomy. J Neurosurg Spine 2009;10:595-602.

11. Ahn Y, Lee SH. Outcome predictors of percutaneous endoscopic lumbar discectomy and thermal annuloplasty for discogenic low back pain. Acta Neurochir (Wien) 2010;152:1695-702.

12. Choi G, Kang HY, Modi HN, Prada N, Nicolau RJ, Joh JY, et al. Risk of developing seizure after percutaneous endoscopic lumbar discectomy. J Spinal Disord Tech 2011;24:83-92.

13. Kim DH, Choi G, Lee SH. Complications in percutaneous endoscopic lumbar diskectomy. In: Endoscopic spine procedures. New York: Thieme; 2011. p.253-67.

14. Ahn Y, Lee SH, Park WM, Lee HY, Shin SW, Kang HY. Percutaneous endoscopic lumbar discectomy for recurrent disc herniation: surgical technique, outcome, and prognostic factors of 43 consecutive cases. Spine (Phila Pa 1976) 2004;29:E326-32.

15. Ahn Y, Lee SH, Lee JH, Kim JU, Liu WC. Transforaminal percutaneous endoscopic lumbar discectomy for upper lumbar disc herniation: clinical outcome, prognostic factors, and technical consideration. Acta Neurochir (Wien) 2009;151:199206.

16. Cho JY, Lee SH, Lee HY. Prevention of development of postoperative dysesthesia in transforaminal percutaneous endoscopic lumbar discectomy for intracanalicular lumbar disc herniation: floating retraction technique. Minim Invasive Neurosurg 2011;54:214-8.

17. Ruetten S, Komp M, Merk H, Godolias G. Use of newly developed instruments and endoscopes: full-endoscopic resection of lumbar disc herniations via the interlaminar and lateral transforaminal approach. J Neurosurg Spine 2007;6:521-30.

18. Ahn Y, Kim JU, Lee BH, Lee SH, Park JD, Hong DH, et al. Postoperative retroperitoneal hematoma following transforaminal percutaneous endoscopic lumbar discectomy. J Neurosurg Spine 2009;10:595-602.

19. Kim WJ, Lim S, Lee S. Pyogenic psoas abscess and secondary spondylodiscitis as a rare complication of percutaneous endoscopic lumbar discectomy: a case report. Joint Dis Rel Surg 2005;16:163-6.

20. Choi KB, Lee CD, Lee SH. Pyogenic spondylodiscitis after percutaneous endoscopic lumbar discectomy. J Korean Neurosurg Soc 2010;48:455-60.

21. Ahn Y, Lee SH. Postoperative spondylodiscitis following transforaminal percutaneous endoscopic lumbar discectomy: clinical characteristics and preventive strategies. $\mathrm{Br} \mathrm{J}$
Neurosurg 2012;26:482-6.

22. Stoller ML, Wolf JS Jr. Endoscopic ureteral injuries. In: Carroll PR, Jordan GH. Traumatic and Reconstructive Urology. Philadelphia: Saunders; 1996. p.199-211.

23. Hellinger J. Technical aspects of the percutaneous cervical and lumbar laser-disc-decompression and -nucleotomy. Neurol Res 1999;21:99-102.

24. Meyer B, Schaller K, Rohde V, Hassler W. The C-reactive protein for detection of early infections after lumbar microdiscectomy. Acta Neurochir (Wien) 1995;136:145-50.

25. Schulitz KP, Assheuer J. Discitis after procedures on the intervertebral disc. Spine (Phila Pa 1976) 1994;19:1172-7.

26. Grane P, Josephsson A, Seferlis A, Tullberg T. Septic and aseptic post-operative discitis in the lumbar spine--evaluation by MR imaging. Acta Radiol 1998;39:108-15.

27. Kylänpää-Bäck ML, Suominen RA, Salo SA, Soiva M, Korkala OL, Mokka RE. Postoperative discitis: outcome and late magnetic resonance image evaluation of ten patients. Ann Chir Gynaecol 1999;88:61-4.

28. Shin JH, Ha KY, Kim KW, Lee JS, Joo MW. Surgical treatment for delayed pyogenic spondylitis after percutaneous vertebroplasty and kyphoplasty. Report of 4 cases. J Neurosurg Spine 2008;9:265-72.

29. Lee SH, Kang BU, Ahn Y, Choi G, Choi YG, Ahn KU, et al. Operative failure of percutaneous endoscopic lumbar discectomy: a radiologic analysis of 55 cases. Spine (Phila Pa 1976) 2006;31:E285-90.

30. Lee S, Kim SK, Lee SH, Kim WJ, Choi WC, Choi G, et al. Percutaneous endoscopic lumbar discectomy for migrated disc herniation: classification of disc migration and surgical approaches. Eur Spine J 2007;16:431-7.

31. Lee DY, Lee SH. Learning curve for percutaneous endoscopic lumbar discectomy. Neurol Med Chir (Tokyo) 2008;48(9):383-8; discussion 388-9.

32. Jang JS, An SH, Lee SH. Transforaminal percutaneous endoscopic discectomy in the treatment of foraminal and extraforaminal lumbar disc herniations. J Spinal Disord Tech 2006;19:338-43.

33. Choi G, Lee SH, Bhanot A, Raiturker PP, Chae YS. Percutaneous endoscopic discectomy for extraforaminal lumbar disc herniations: extraforaminal targeted fragmentectomy technique using working channel endoscope. Spine (Phila Pa 1976) 2007;32:E93-9.

34. Ahn Y, Lee SH, Park WM, Lee HY. Posterolateral percutaneous endoscopic lumbar foraminotomy for L5-S1 foraminal or lateral exit zone stenosis. Technical note. J Neurosurg 2003; 99(3 Suppl):320-3. 